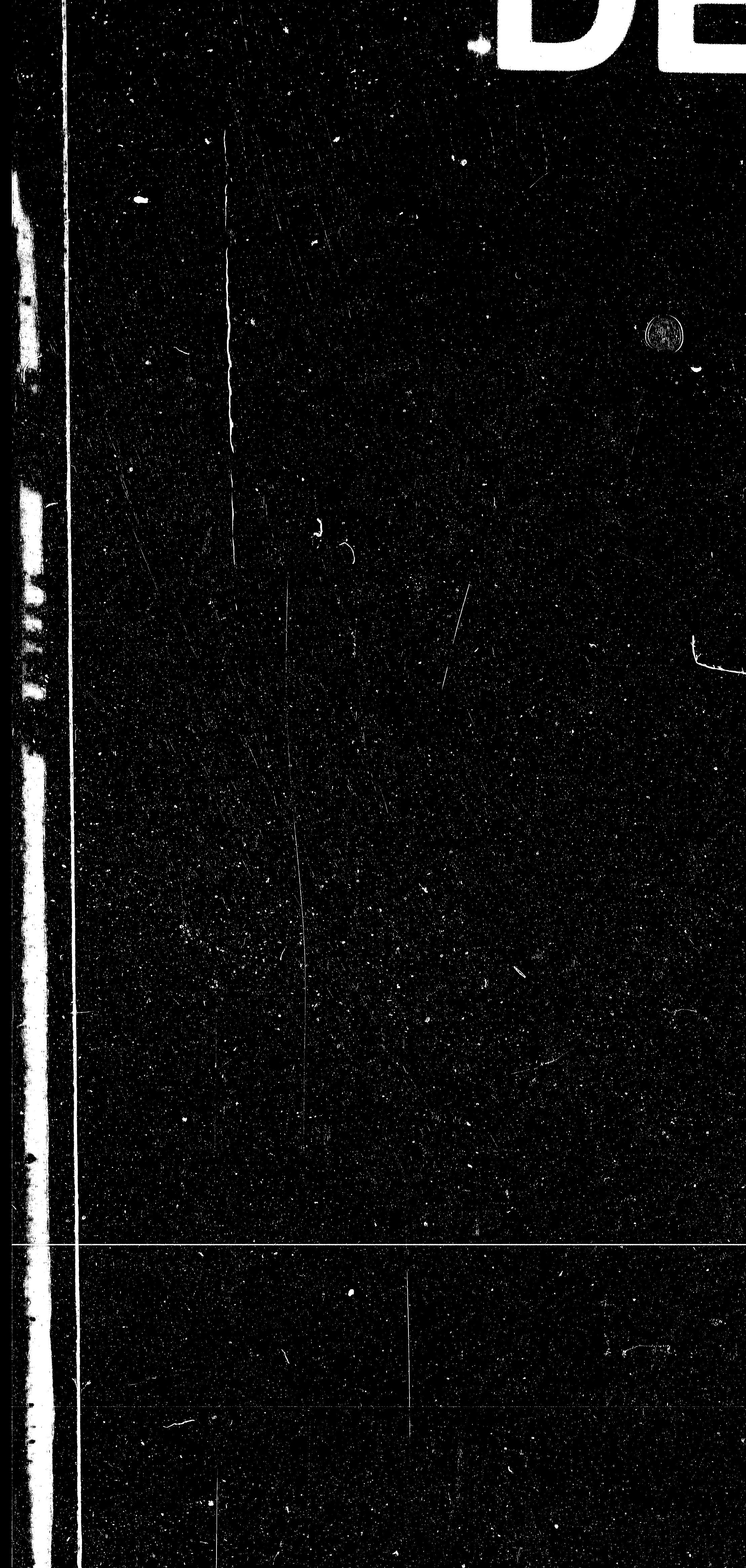



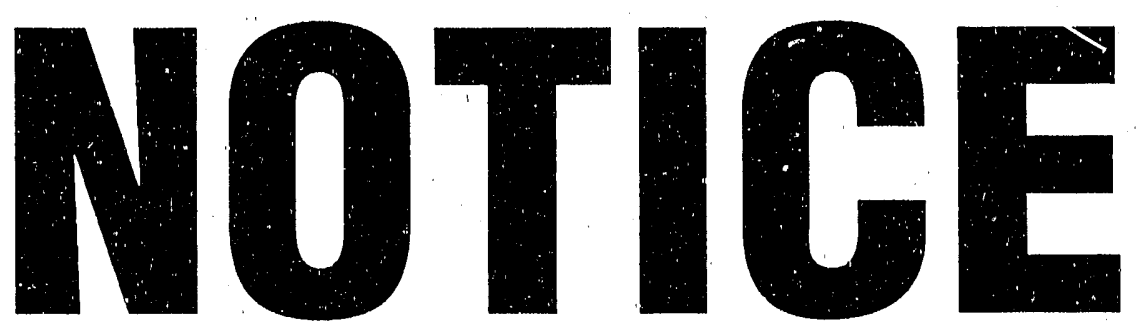

\section{CERTAIN DATA}

\section{CONTAINED IN THIS}
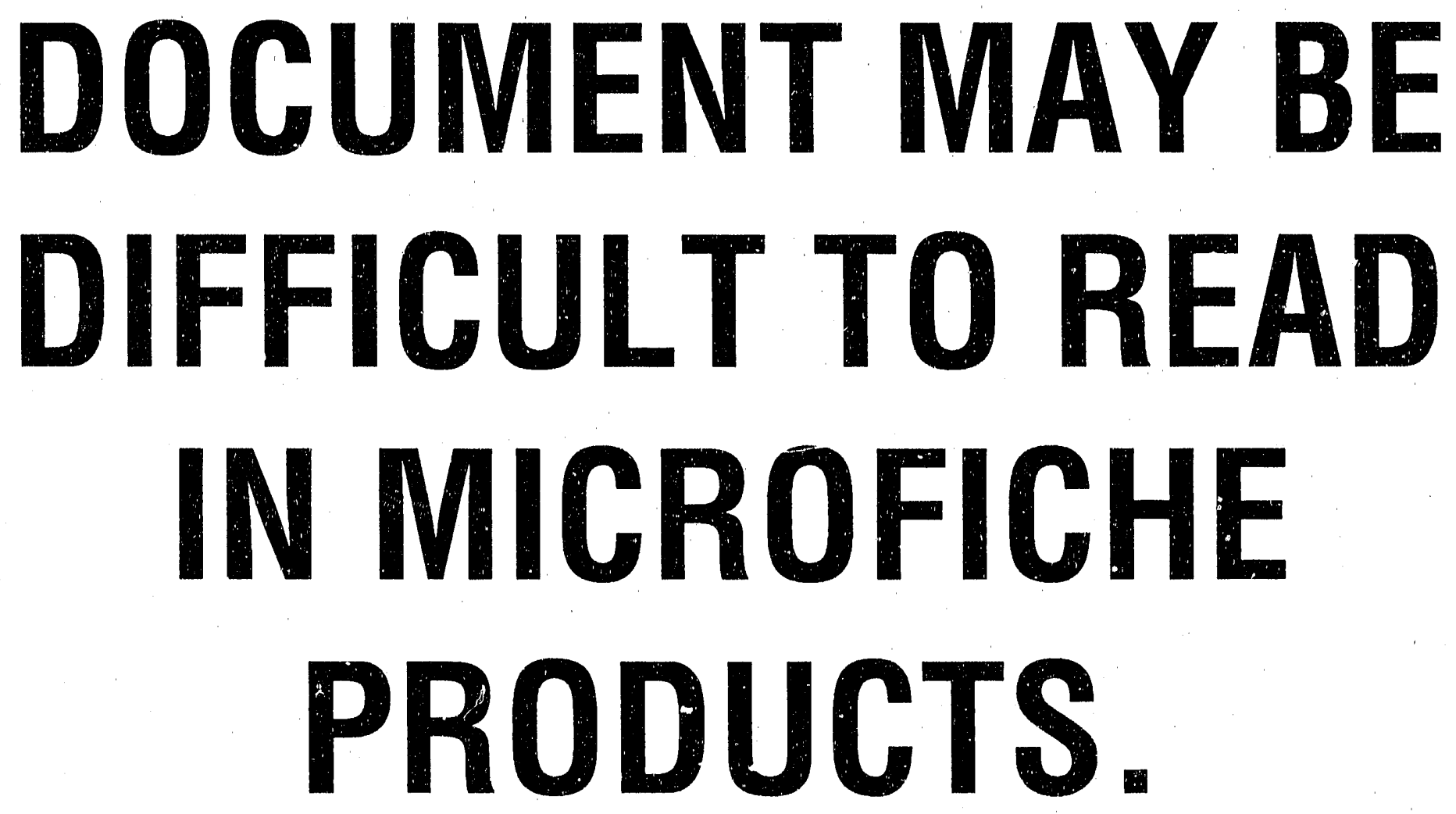


\title{
PHOTOLUMINESCENCE AND STRUCTURAL CHARACTERIZATION OF MeV ERBIUM IMPLANTED SILICA GLASS
}

\author{
A. Polman, D.C. Jacobson, A. Lidgard ${ }^{a}$ and J.M. Poate \\ AT\&T Bell Laboratories \\ 600, Mountain Avenue, Murray Hill, NJ 07974
}

\author{
G.W. Amold
}

Sandia National Laboratories

Albuquerque, NM 87185

\begin{abstract}
Suprasil glass (amorphous $\mathrm{SiO}_{2}$ ) has been implanted with $2.9 \mathrm{MeV}$ Er ions at fluences of $3.4 \times 10^{15}$ and $3.4 \times 10^{16}$ ions $/ \mathrm{cm}^{2}$. Photoluminescence spectra of implanted samples show a clear luminescent transition around $\lambda=1.54 \mu \mathrm{m}$, corresponding to an intra-4f transition of $\mathrm{Er}^{3+}$. Fluorescence decay tinies are in the range $1.8 \mathrm{~ms}$, depending on implantation fuence and annealing trearment. $U V$ absorption and $I R$ refiertion spectroscopy are employed to characierize beam-induced defects in the sllica network. The results indicate that defects in the silica nerwork play an important role in the energy transfer processes in the Er:silica sysiem.
\end{abstract}

a) on leave from Dept. of Physics, Royal Inst. of Technology, Stockholm, Sweden.

\section{INTRODUCTION}

Optical doping of insulators and semiconductors using ion beams is a new and unexploited area in the field of ion-solid interactions. Until today, the limited number of investigations concerns implantation of $\mathrm{Si}_{1}{ }^{1-3} \mathrm{MI} \cdot \mathrm{V}$ semiconductors, ${ }^{3-5} \mathrm{LiNbO}_{3}{ }^{6}$ and silica glass, ${ }^{7}$ with rare-earth olements such as $\mathrm{Er}, \mathrm{Nd}$ and $\mathrm{Yb}$. These elements have the interesting property that, when incorporated with trivalent charge state in a solid host, their electronic energy levels differ only slightly from those of the free ion. This is a result of the fact that the $4 f$ orbitals of trivalent rare-earths are effectively shielded by the outer lying closed $5 s^{2}$ and $5 p^{6}$ shells. The Er:silica-glass system is of particular interest because Er has an intra- $4 f$ cransition at a wavelength $(\lambda)$ of $1.54 \mu \mathrm{m}$, coinciding with the low-loss window of standard silica-based telecommunications fiber.

Recently, we have shown that it is possible to incorporate optically active $\mathrm{Er}$ in thin silica glass films on a Si substrate using a $\mathrm{MeV}$ ion beam. ${ }^{7}$ In this paper we concentrate on $\mathrm{MeV}$ Et implantation in Suprasil silica glass. This material is available in bulk form, which enables ultraviolet (UV) absorption and infrared (IR) reflection spectroscppy 
studies to be made in order to investigate radiation-induced changes in the silica network. These data are correlated with a photoluminescence study in which the intra- $4 f$ transitions in the Er:silica system are investigated.

\section{EXPERIMENTAL}

High-purity fused silica glass (amorphous $\mathrm{SiO}_{2}$ ) samples, commercially known as Suprasil 1, were implanted on one side with $2.9 \mathrm{MeV} \mathrm{Er}^{++}$ions. Implantation was done at room temperature and the fluences were either $3.4 \times 10^{15}$ or $3.4 \times 10^{16}$ ions $/ \mathrm{cm}^{2}$. The Er concentration profiles as a function. of depth were determined using Rutherford backscattering spectrometry. The as-implanted profile was nearly Gaussian shaped with the peak at $1.04 \mathrm{\mu m}$ depth and a full width at half-maximum (FWHM) of $0.46 \mu \mathrm{m}$. The Er peak concentration was 0.1 at.\% or 1.0 at.\% for low- and high-fluence implanted samples, respectively. Thermal annealing for one hour at $900^{\circ} \mathrm{C}$ was carried out on some samples using a standard tube-furnace at a base pressure below $10^{-6}$ Torr. Annealing did not lead to any measurable diffusion of Er.

Photoluminescence (PL) measurements were performed at room temperature, using the $\lambda=488 \mathrm{~nm}$ line of an $\mathrm{Ar}^{+}$laser as a pump source. Time-resolved fluorescence decay measurements were performed at $\lambda=1.536 \mu \mathrm{m}$. The $850 \mu \mathrm{s}$ FWHM excitation pulse was obtained by mechanical chopping and had rise- and fall times of $150 \mu \mathrm{s}$. Decay data. were collected using a digitizing oscilloscope. Optical absorption measurements were performed using a dual-beam Cary 23 spectrophotometer and all measurements wers performed against an unimplanted sample in the reference beam. IR reflection spectroscopy was performed in the lattice-mode region of the infrared using a Nicolet 60 SX FTIR instrument.

\section{RESULTS}

\section{a) Photoluminescence}

Fig. 1 shows a photoluminescence spectrum for a sample implanted with $3.4 \times 10^{15}$ ions $/ \mathrm{cm}^{2}$ and annealed at $900^{\circ} \mathrm{C}$. Clearly, a luminescence peak is observed around $\lambda=$ $1.54 \mu \mathrm{m}$. This wavelength coincides with the wavelength of the transitions between the frrst excited manifold ${ }^{4} I_{13 / 2}$ and the ${ }^{4} I_{13 / 2}$ ground manifold of $\operatorname{Er}^{3+}\left(4 f^{11}\right.$ ) (Ref. 8). The PL peak is composed of a main peak at $\lambda=1.536 \mu \mathrm{m}$ and a side peak with somewhat lower intensity at $\lambda=1.552 \mu \mathrm{m}$. A spectrum for a sample implanted at 10 times higher fuence and annealed at $900^{\circ} \mathrm{C}$ is also shown in Fig. 1. In the figure, its amplitude is reduced by a factor 9 . The double-peak structure is less pronounced and the spectrum is somewhat broader. Spectra for unannealed samples were roughly similar to those for the annealed samples in Fig. 1, apart from their intensity. Table I lists the integrated PL intensities for all implanted samples. It can be seen that thermal annealing increases the PL intensities by a factor 4 or 7 for low- and high-fluence implants respectively, For the annealed samples the integrated PL intensities are proportional to the Er fluence.

Time-resolved measurements of the fluorescence decay showed a single-exponential decay for all samples. ${ }^{3}$ The $1 / e$ times range from $1.8 \mathrm{~ms}$ and are listed in Table I. As can be seen, themal annealing increases the decay time. When the Er concentration is increased, the decay time becomes shorter.

\section{b) UV Absorption}

Fig. 2 shows a compllation of optical absorption spectra of samples implanted with $3.4 \times 10^{\text {Is }}$ ions $/ \mathrm{cm}^{2}$ (as-implanted and implunted + annealed at $900^{\circ} \mathrm{C}$ ) and a sample 
implanted with $3.4 \times 10^{16}$ ions $/ \mathrm{cm}^{2}$ (as-implanted only). For the as-implanted samples an absorption structure is found between $\lambda=185$ and $280 \mathrm{~nm}$. Absorption in this wavelength region is well-documented and has been identified to correspond to two types of defects: the E'-center (an O-vacancy opposite an electron in a dangling Si $s p^{3}$ orbital, in the spectrum centered around $215 \mathrm{~nm}$ ) ${ }^{10}$ and the $B_{2}$-center (presumably related to an O-vacancy which has trepped two elections, at about $245 \mathrm{~nm})^{11}$. Both defects are known to be mainly produced as a result of the collisional component of the ion-energy deposition process.

As is evident from Fig. 2, the high-fluence implant yields a higher absorption than the low-fluence implant. This indicates that there is no saturation in the concentration of beam-induced point defects for $2.9 \mathrm{MeV}$ Er fluences up to $-10^{16} \mathrm{ions} / \mathrm{cm}^{2}$. For this fuence the number of ion-induced displacements per atom (dpa), estimated using TRIM $^{12}$ amounts $10-35 \mathrm{dpa}$. After annealing at $900^{\circ} \mathrm{C}$, the low-fluence implanted sample shows no noticeable absorption in the $185.400 \mathrm{~nm}$ wavelength region indicating that all $E^{\prime}$ and $B_{2}$ centers are annealed out. Indeed, it has been observed earlier that point defects of the type considered here anneal out at temperatures of $400{ }^{\circ} \mathrm{C}$ and higher. ${ }^{13}$

Absorption measurements were also performed in the wavelength region around the luminescent transition at $\lambda=1.54 \mu \mathrm{m}$ and no noticeable defect-related absorption was found. This is an important finding for future use of Er-implanted Suprasil glass in optical devices. Another concern has been that high concentrations of Er might lead to colloid formatior and result in undesired light-scattering. There is no evidence for colloidal absorption in the data of Fig. 2.

\section{c) IR Reflection}

Fig. 3 shows IR reflection spectra for samples implanted at $3.4 \times 10^{15}$ ions $/ \mathrm{cm}^{2}$ (asimplanted and implanted + annealed at $900^{\circ} \mathrm{C}$ ) and $3.4 \times 10^{16}$ ions $/ \mathrm{cm}^{2}$ (as-implanted only). A spectrum for an unimplanted sample is also shown and shows a peak at around $1128 \mathrm{~cm}^{-1}$ corresponding to the Si-O-Si stretch vibration. ${ }^{14}$ The production of damage by the ion beam causes a shift of this peak to lower wavenumber. This has been observed earlier and is thought to be due to an increase in the mean $\mathrm{Si}-\mathrm{O}$ bond length and a decrease in the mean equilibrium bridging angle (normally $144^{\circ}$ ). ${ }^{15} \mathrm{Also}$, a small damage band is observed around $1015 \mathrm{~cm}^{-1}$. This mode is believed to be due to dangling Si-O groups. ${ }^{14}$ It is interesting to note that only a slight difference is observed between the spectra for the low- and high-fluence as-implanted samples. This suggests that a saturation in network distortion occurs above a $2.9 \mathrm{MeV}$ Er fluence in the order of $-10^{15}$ ions $/ \mathrm{cm}^{2}(-4 \mathrm{dpa})$.

\section{DISCUSSION}

All implanted samples show a luminescence peak around $\lambda=1.54 \mu \mathrm{m}$. For the high-fluence annealed implant, the double-peak structure in the PL spectra becomes less apparent and the spectrum becomes wider, which indicates a wider configurational distribution of Er sites at high concentration. Although the UV absorption and IR refiection measurements of the as-implanied samples clearly show the presence of beaminduced defects and distortions in the silica network, it appears that these defects do not prevent the Er from being incorporated on an optically active site. For Er to be optically active, it needs to be incorporated in its trivalent state. This possibly takes place through 
an ionic bonding to non-bridging oxygen ions in the silica network. Thermal annealing might stimulate formation of these Er-O bonds, which can partly explain the increase in luminescence intensity upon annealing.

Thermal anrealing also increases the fluorescence decay time of implanted samples (see Table I). This suggests that in as-implanted samples the excited state is partly depleted through non-radiative paths. These paths are presumauly defect-related and hence a thermal treatment, which (partly) anneals out the corresponding defects (see UV and $I R$ spectra), results in a longer decay time. The decay time for the unannealed lowfluence implanted sample is significantly longer than for the unannealed high-fuence implanted sample ( 5.7 vs. $1.2 \mathrm{~ms}$ ). Since the UV and $I R$ daca show that the main difference between those samples is the point defect concentration, it is concluded that these are the defects responsible for the non-radiative decay processes. For annealed samples, the decay times for high-and low-fluence implanted sampies are also different. This suggests that concentrarion-quenching effects, involving energy transfer processes between rare-earth ions, ${ }^{8}$ might play a role at concentrations of at least -1 a.t.\%

An increase in PL decay time also results in an increased PL intensity. To first order, assuming a simple process involving two different probabilities for radiative and nonrediative ${ }^{4} I_{13 / 2} \rightarrow{ }^{4} I_{15,2}$ transitions, the $\mathrm{PL}$ intensity would be proportional to the measured decay time of the ${ }^{4} I_{13 / 2}$ excited state. ${ }^{9}$ Comparing the data in Table I for unannealed and annealed samples at a given Er fluence, it is seen that the PL intensity increases more than linearly with decay time. This indicates that thermal annealing, apart from reducing the defect concentration, also increases the total number of optically active Er ions. Mor complicated processes e.g. involving annealing of defect states above the ${ }^{4} I_{13 / 2}$ level 1 dight also play a role.

\section{CONCLUSION}

$2.9 \mathrm{MeV}$ Er implanted Suprasil glass shows a strong luminescent transition around $\lambda$ $=1.54 \mu \mathrm{m}$ corresponding to an intra-4f transition of $\mathrm{Er}^{3+}$. Fluorescence decay times are in the range $1.8 \mathrm{~ms}$. Beam-induced def is in as-implanted samples can be identified using UV and IR spectrosopy. Thermal annealing reduces the defect concentration and increases the luminescence decay time. This indicates that defects in the silica network (presumably point defects) play an important role in the energy transfer processes within the Er:silica system. An increase in PL intensity is observed after annealing and is atributed to the increase in decay time as well as an increase in the number of optically active $\mathrm{Er}^{3+}$ ions. This correlation between UV absorption, IR reflection and luminescence measurements enabled us to converge results on radiation damage in glass and oprical activity of implanted Er into a clear picture.

The work of G.W. Arnold was supported by the U.S. Department of Energy under contract number DE-A.C04-76DP00789.

\section{References}

1. Y.S. Tang, K.C. Heasman, W.P. Gillin and B.J. Sealy, Appl. Phys. Lett, 55, 432 (1989)

2. D. Moutonnet, H. l'Haridon, F.N. Favennec, M. Salvi, M. Gauneau, F. Arnoud d'Avitaya and J. Chroboczek, Mater. Sci. Engin. B4, 75 (1989) 
3. H. Ennen, J. Schneider, G. Pomrenke and A. Axmann, Appl. Phys. Lett. 43, 943 (1983)

4. G.S. Pomrenke, H. Ennen and W. Haydl, J. Appl. Phys. 59, 601 (1986)

5. G. Aszodi, J. Weber, Ch. Uihlein, L. Pu-lin, H. Ennen, U. Kaufmann, J. Schneider and J. Windscheif, Phys. Rev. B31, 7767 (1985)

6. R. Brinkmann, C. Bruchal, S. Mohr, W. Sohler and H. Suche, Proc. Integr. Phot. Res. Conf, Hiltonhead SC, USA, March 26-28 (1990)

7. A. Polman, A. Lidgard, D.C. Jacobson, P.C. Becker, R.C. Kistler, G.E. Blonder and J.M. Poate, submitted to Appl. Phys. Lett.

8. S. Hufner, Optical Spectra of Transparent Rare-Earth Compounds (Acaden ric, New York, 1978)

9. A. Polman, D.C. Jacobson and J.M. Poate, to be published

10. see e.g. F.J. Feigl, W.B. Fowler and K.L. Yip, Solid State Commun. 14, 225 (1974)

11. G.W. Amold, IEEE Trans. Nucl. Sci. NS-20, 220 (1973)

12. J.P Biersack and L.J. Haggmark, Nucl. Instr. and Meth. 174, 257 (1980)

13. U. Katenkamp, H. Karge and R. Prager, Rad. Effecis 48, 31 (1980)

14. G.W. Amold, The Physics of MOS Insulators, edited by G. Lucovsky, S.T. Pantelides and F.L. Galeneer (Pergamon, NY, 1980), p. 112

15. G.E. Walrafen and M.S. Hokmabadi, in Strucrure and Bonding in Noncrystalline Solids (Plenum, NY), p. 185

Table I Integrated PL intensities and fuorescence decay times of Er-implanted silica samples.

\begin{tabular}{|c|c|c|c|}
\hline $\begin{array}{c}\text { fluence } \\
\left(\text { lons } / \mathrm{cm}^{2}\right)\end{array}$ & annealing & $\begin{array}{c}\text { PL intensity } \\
\text { (a.u. })\end{array}$ & $\begin{array}{c}\text { decay time } \\
\text { (ms) }\end{array}$ \\
\hline \multirow{2}{*}{$3.4 \times 10^{15}$} & - & $1.00 \pm 0.03$ & $3.2 \pm 0.1$ \\
\cline { 2 - 4 } & $900^{\circ} \mathrm{C}, 1 \mathrm{hr}$ & $3.5 \pm 0.1$ & $7.9 \pm 0.2$ \\
\hline \multirow{2}{*}{$3.4 \times 10^{16}$} & - & $5.3 \pm 1.1$ & $1.2 \pm 0.1$ \\
\cline { 2 - 4 } & $900^{\circ} \mathrm{C}, 1 \mathrm{hr}$. & $34.4 \pm 1.9$ & $5.7 \pm 0.1$ \\
\hline
\end{tabular}

Figure Captions

Fig. 1 Room-temperature photoluminescence spectra for silica glass implanted with $2.9 \mathrm{MeV} \mathrm{Er}$ at two different fluences (indicated in the figure) and annealed at $900^{\circ} \mathrm{C}$ for $1 \mathrm{hr}$. Both measurements were performed using the same pump 
power $(\lambda=488 \mathrm{~nm})$.

Fig. 2 Optical absorption measurements for silica glass implanted with $3.4 \times 10^{15} \mathrm{Er}$ ions $/ \mathrm{cm}^{2}$ (as-implanted and implanted + annealed) and $3.4 \times 10^{16} \mathrm{Er}$ ions $/ \mathrm{cm}^{2}$ (implanted + annealed).

Fig. 3 Infrared reflection measurements for silica glass implanted with $3.4 \times 10^{15} \mathrm{Er}$ ions $/ \mathrm{cm}^{2}$ (as-implanted and implanted + annealed) and $3.4 \times 10^{16} \mathrm{Er}$ ions $/ \mathrm{cm}^{2}$ (implanted + annealed). A spectrum for an unimplanted sample is shown for reference.
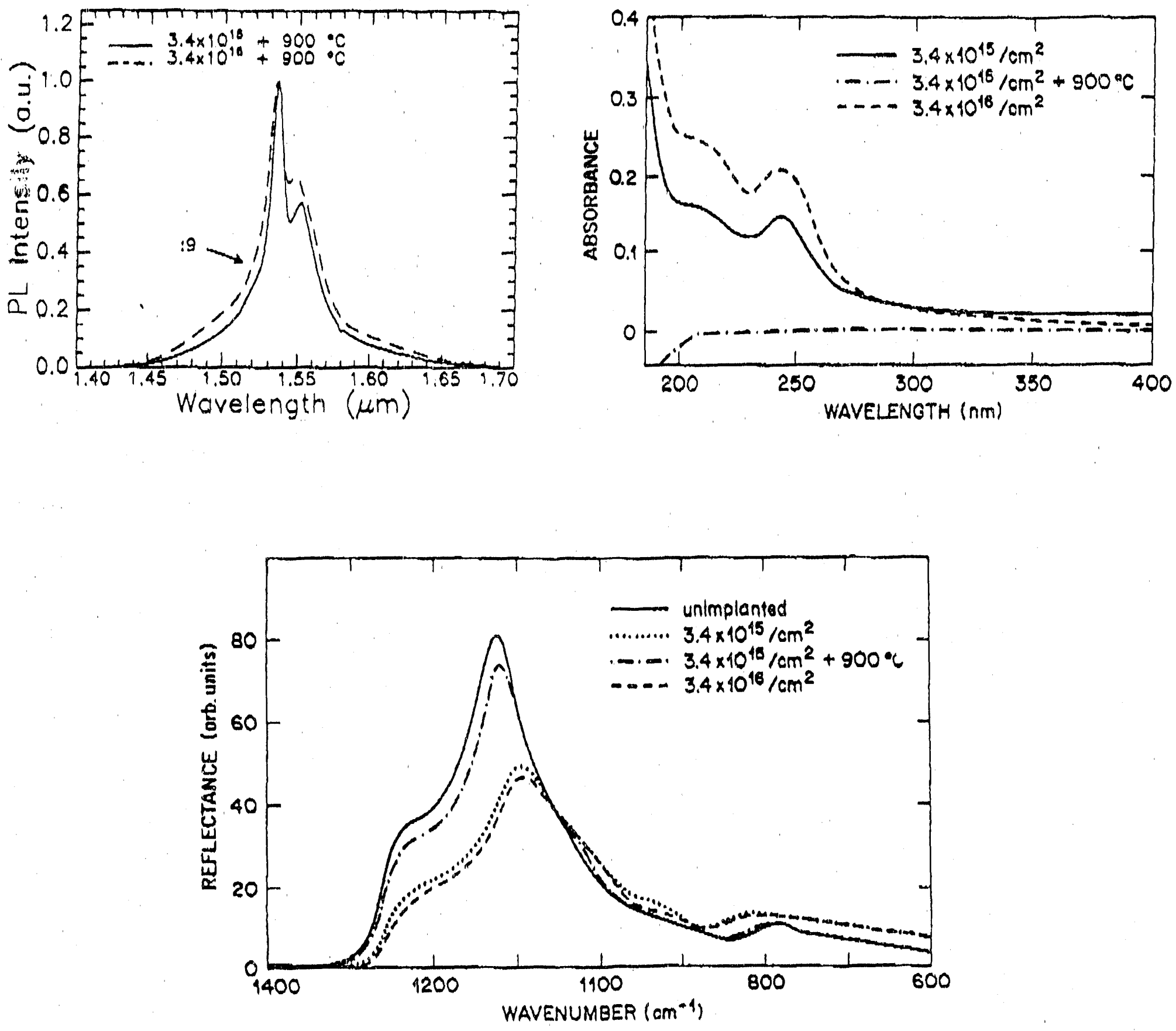


\section{DISCLAIMER}

This report was prepared as an account of work sponsored by an agency of the United States Government. Neither the United States Government nor any agency thereof, nor any of their employees, makes any warranty, express or implied, or assumes any legal liability or responsibility for the accuracy, completeness, or usefulness of any information, apparatus, product, or process disclosed, or represerits that its use would not infringe privately owned rights. Reference herein to any specific commercial product, process, or service by trade name, irademark, manufacturer, or otherwise does not necessarily constitute or imply its endorsement, recommendation, or favoring by the United States Government or any agency thereof. The views and opinions of authors expressed herein do not necessarily state or reflect those of the United States Government or any agency thereof. 

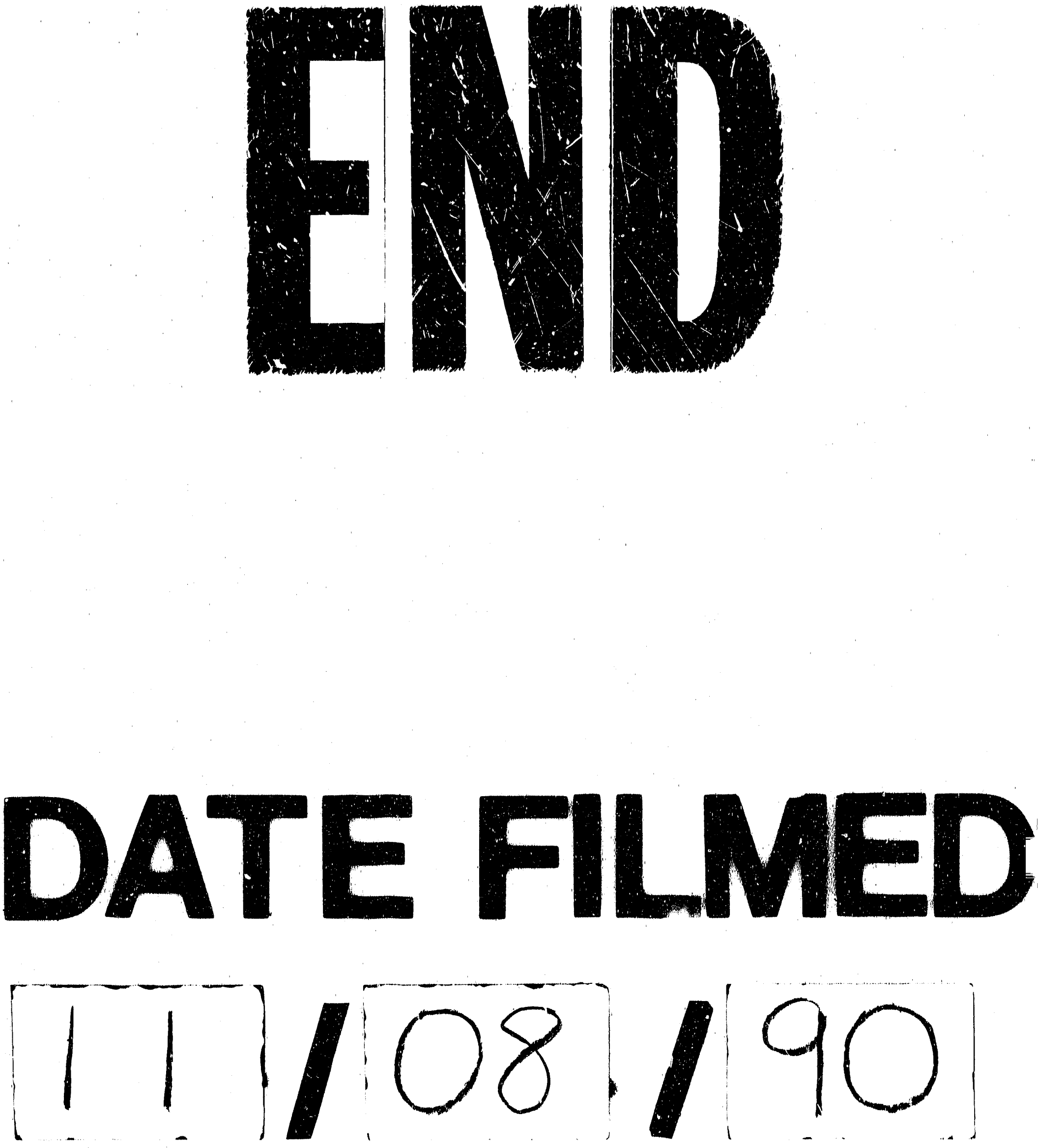
